\title{
An Experimental Study of the Geometrical Effect on the Performance of an Agricultural Air Induction Nozzle
}

\author{
Reza Alidoost Dafsari ${ }^{1}$, Milad Khaleghi Kasbi ${ }^{1}$, Seunghwa $\mathrm{Yu}^{2}$, Yong $\mathrm{Choi}^{2}$ Jeekeun Lee $^{\star 1}$ \\ ${ }^{1}$ Department of Mechanical system engineering, Chonbuk National University, Jeonju, South \\ Korea \\ ${ }^{2}$ Rural Development Administration, R\&D center, Jeonju, South Korea \\ ${ }^{*}$ Corresponding author email: leejk@jbnu.ac.kr
}

\begin{abstract}
Target spraying has become of prime interest in the agricultural field to avoid the drift or rebound of the chemicals while spraying and consequently minimize water and soil pollution. Air induction nozzles are the means to spray chemicals such as pesticide in large size droplets which can resist the drift due to a potential wind and to minimize the rebound off the target with an explosion of induced air bubbles. To experimentally investigate the effect of the geometry of the air induction nozzle on its performance, a number of components are designed and manufactured to control various dimensions. The spray structure and air to liquid ratio were captured using planner imaging Mie scattering system and flowmeters respectively. Moreover, the mean droplet size was measured using a Malvern particle sizer. The parametric study showed the influence of each geometrical component on the resultant behavior. The result can help the nozzle designers to optimize the design target and enhance atomization efficiency.
\end{abstract}

\section{Keywords}

Agricultural nozzle, Air induction nozzle, Air to liquid mass flow ratio (ALR), target spraying

\section{Introduction}

Agricultural nozzles are commonly used to deliver pesticides and other essential chemicals to plants. Some droplets may not reach the intended target during spraying due to drift, runoff, and rebound. Drift potential from agricultural nozzles in windy conditions has been found a major challenge leading to water and soil pollution with risks for fauna, flora, and humans [1]. The drift of droplets may be attributed to multiple factors [2-6]. With the presence of a side wind, the probability of whether the droplets reach the target depends particularly on their size and velocity [6-9]. Slow or small droplets may easily drift with even low-velocity wind. The size and velocity of spray droplets are related to the geometry of the nozzle and the injection pressure [10-12]. On the other hand, a cluster of small droplets can enhance the coverage ratio on the surface of a leaf better than large droplets.

In field crops, the most popular nozzle for pesticide delivery has been the flat fan nozzle, which also has major drawbacks. Flat fan nozzles generate droplets in a size range varying between extremely fine to ultra-coarse ( $<60$ to $>650$ micrometers) [13] among which, fine droplets (smaller than $200 \mu \mathrm{m}$ ) are likely to drift before reaching the target [14]. In the late 20th century, the air induction nozzle (AIN), also known as the Venturi nozzle, was introduced. An AIN is basically a conventional nozzle with an additional jet pump (Venturi) employed to induce air into the mixing chamber and consequently discharge a bubbly liquid sheet. The jet pump (ejector) theory suggests a change in flow path area resulting in pressure and velocity difference in ejecting fluid creating a Venturi effect $[15,16]$. The resulting mixture of air and liquid, exiting the nozzle in the form of a bubbly sheet, interacts with the surrounding air, initially 
disintegrating into ligaments and further breaks up into large droplets including air bubbles. AINs are able to produce significant quantities of included air (air bubbles within the drop) [17, 18]. Drift resistance is not the only advantage of AINs over conventional nozzles. Conventional coarse-drop-generating nozzles have a higher flow rate, producing larger drops of liquid with high momentum and kinetic energy. Therefore, when these coarse droplets reach both the target leaves bounce and fall to the ground [19] where air-induced drops with lower velocity can distribute better by exploding and splashing on the surface [20]. A droplet with a lower velocity produces a smaller maximum spread [21].

The use of drift-reducing nozzles has globally increased, especially in Europe [22]. Drift reduction nozzle design essentially requires a knowledge of the multiphase dynamics of the geometric parameters. Drift values obtained by implementing field drift experiments are timeconsuming, with poor repeatability because of the wind velocity fluctuations. Hence, laboratory-scale studies have simulated actual field situations to study this phenomenon. Drop size and uniformity are governed by geometrical dimensions, mainly the nozzle tip and discharge orifice; however, injection conditions, such as point axial distance, injection pressure, and temperature, as well as working fluid physical properties are undeniably important $[23,24]$. Therefore, the optimization of nozzle performance requires further study. The main objective of this study is to investigate the effect of geometrical design parameters for an AIN based on jet pump theory on the air to liquid mass flow ratio (ALR) and drift reduction of the delivered spray.

\section{Material and Methods Nozzle design}

The present study as a part of a systematic parametric investigation of the geometrical effect on the nozzle performance was experimentally carried out by designing a set of nozzle components. Hence, a number of laboratory-scale experiments were designed to simulate real field situations to illustrate spray behavior.

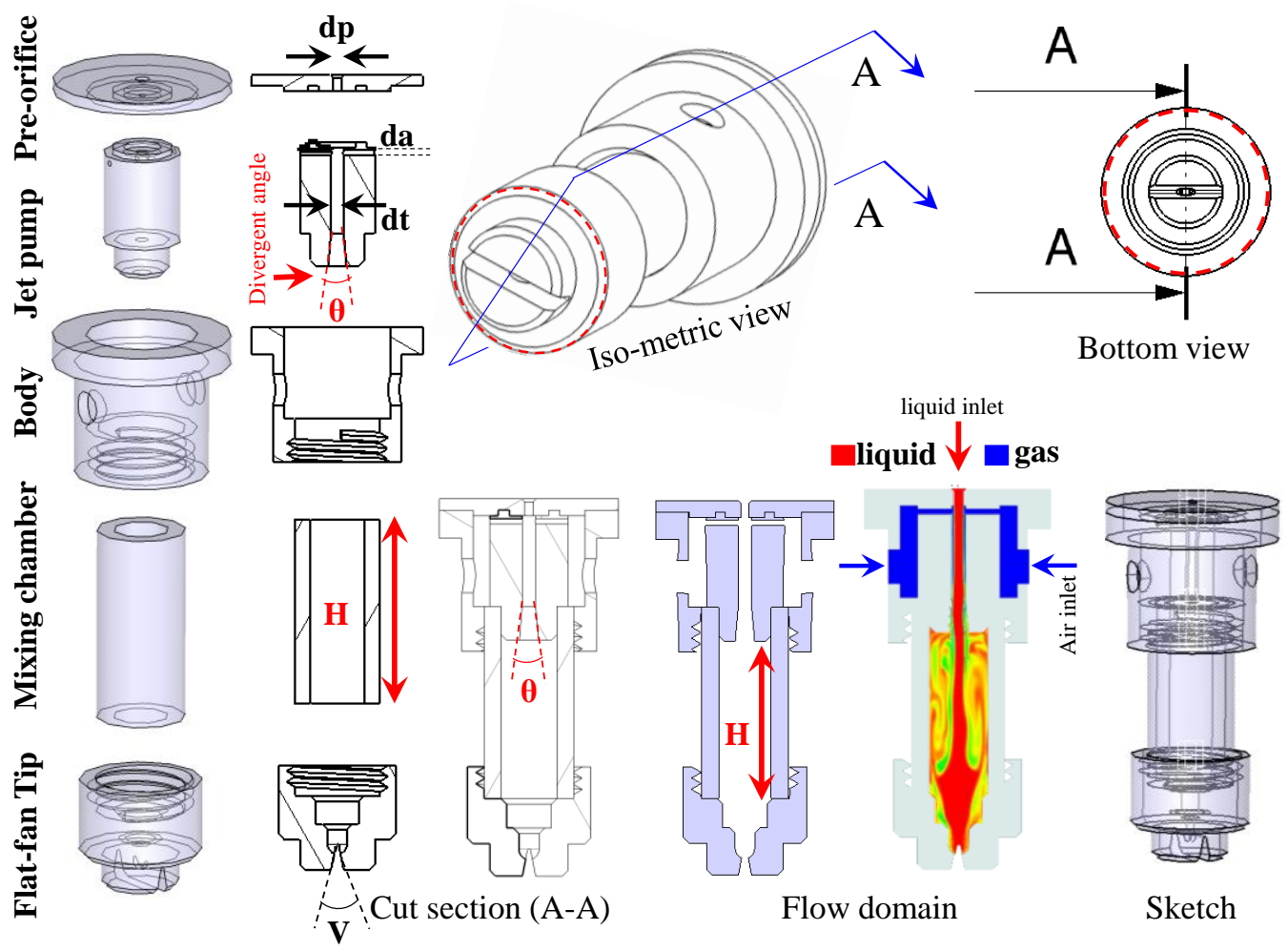

Figure 1 Schematic of the designed and tested nozzle and corresponding components 
Figure 1 shows the geometry of the in-house designed nozzle with the definition of various components. Although all dimensions of air and liquid passages are being systematically studied in this project, the current document provides results about the effect of jet pump divergent angle $(\boldsymbol{\theta})$ and the mixing chamber length $(\boldsymbol{H})$. As schematically defined in Fig. 1 , liquid enters from the liquid inlet of the pre-orifice into jet-pump where its velocity and pressure are affected by the jet-pump geometry. The geometry of the Venturi part sucks air into the main flow stream. Air enters through the body air passage and finds its way into the gas path highlighted in blue in the cut section and reaches the liquid throat. At this phase, gas and liquid interact and mix in the mixing chamber.

\section{Experimental setup}

An overall view of the experimental apparatus is schematically given in Fig. 2, where water, as the working fluid, was pressurized with nitrogen gas in a pressure tank and supplied to the test nozzles. The liquid injection pressure was controlled by a Kulite ETM-375-500A pressure transducer with a stable, low-noise, standard output signal with $1 \%$ accuracy. The flow rate was measured using a gear-type mass flow meter (Badger, IND OG-1/4"-S-S-1-V-LF, standard $0.03 \% \mathrm{Rd} \pm 1.0 \%$ full scale (standard error of the mean $\mathrm{SEM}$ )) coupled with a Kyongin KM2 flow indicator. A Siagro FS4008-50 gas hot-wire flow sensor, with an accuracy of $1.5 \pm 0.2$ full scale (SEM) and a pressure decrease of $<600 \mathrm{~Pa}$, was placed before the air orifice to measure the airflow rate. The signals of the sensors and flowmeters were all sent through a National Instrument data acquisition board to an in-house LabView code to transform from voltage or current into pressure and flowrate.

The presented spray images identifying the bubbly sheet and droplet rebound were taken using a high-speed camera (Photron FASTCAM SA-X2 Type: 1000 K-C3 using a Nikon lens; Rayfact PF10545 MF-UV) at a frame rate of 50,000 and 100000 frames/sec respectively and a shutter speed of $1 / 200,000 \mathrm{sec}$. A backlight LED was set as the illumination source for shadowgraphy. Mie scattering imaging was performed for capturing spray structure in which a Powerview 4MP camera was synchronized to an Nd:Yag laser with a maximum energy of

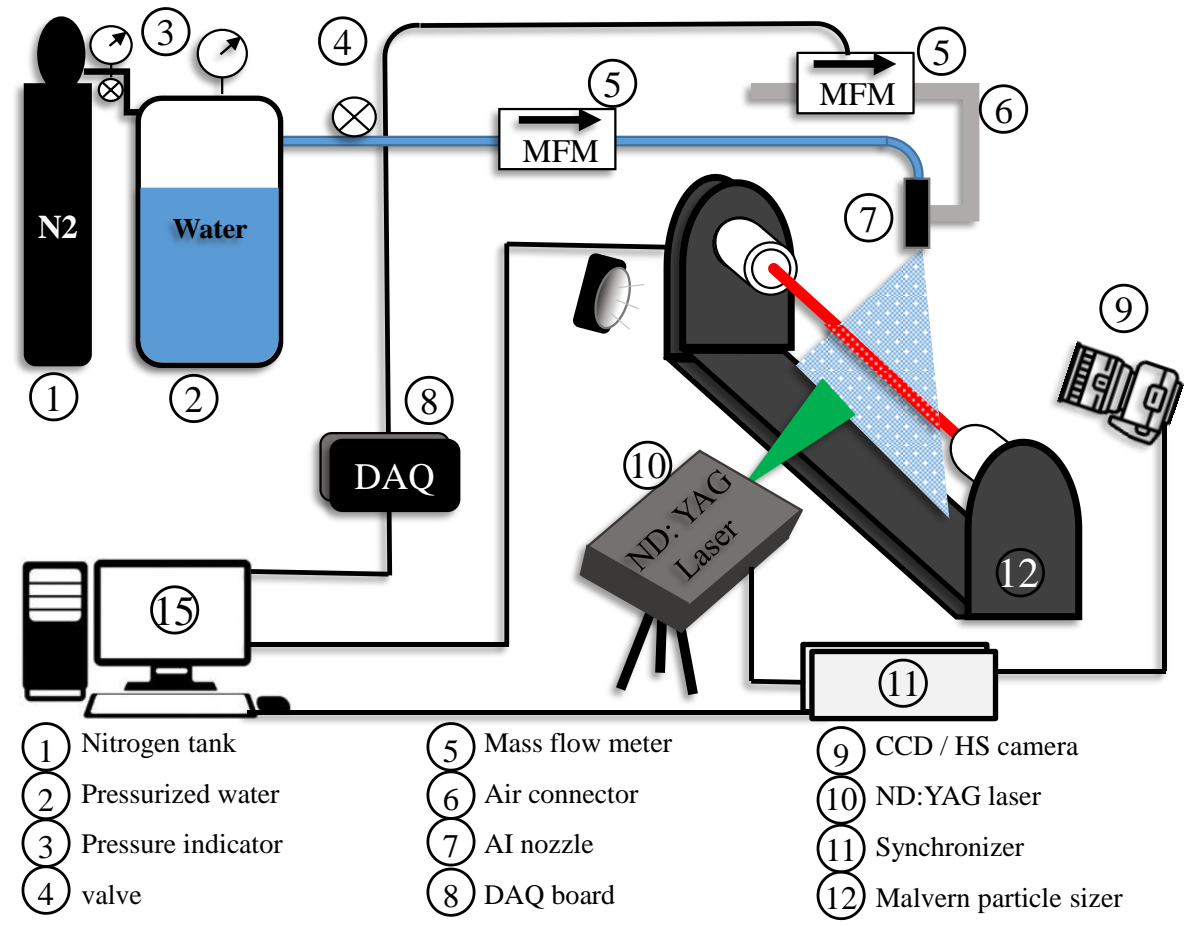

Figure 2 Schematic of experimental setup 
$120 \mathrm{~mJ} /$ pulse, a $15-\mathrm{Hz}$ pulse rate illuminating the spray sheet positioned perpendicular to the camera at $100 \mathrm{~cm}$ distance from the nozzle axis. The droplet mean size was rendered by a laser diffraction method (Malvern Spraytec).

The geometry of the studied components is given in Table 1. In this document, the effect of mixing chamber length $(H)$ and jet-pump divergent angle is varied while keeping all the other dimensions constant.

Table 1 - Components combinations for effect of mixing chamber length and jet pump divergent angle

\begin{tabular}{c|ccccc}
\hline Div $[\theta]($ deg $)$ & $\mathrm{H}(\mathrm{mm})$ & $\mathrm{dp}(\mathrm{mm})$ & $\mathrm{dt}(\mathrm{mm})$ & $\mathrm{da}(\mathrm{mm})$ & $\mathrm{V}(\mathrm{deg})$ \\
\hline 0 & 7 & & & & \\
10 & 11 & 0.8 & 1.2 & 0.5 & 22 \\
20 & 14 & & & & \\
40 & 17 & & & & \\
\hline
\end{tabular}

\section{Results and Discussion \\ Spray structure}

The structure of spray resulting from AIN differs from the conventional flat fan nozzle as given in Fig. 3. Air induction nozzles utilize a larger orifice opening to let the bubbly mixture discharge as a bubbly sheet. Therefore, a thicker liquid sheet and longer breakup length are expected resulting in larger droplets. The general structure of a flat fan - whether micro air bubbles included or not - consists of a thin liquid sheet disintegrating into ligaments due to distortion of the sheet and further into droplets due to aerodynamic forces and instability rules.

As the spray angle measurement is schematically shown in Fig.4, the captured spray instantaneous images were first averaged and then binarize from gray-scale to black and white with applying a threshold. Binarized images show a clear edge to detect. This represents the mean spray angle where the instantaneous images showed no more than $8 \%$ deviation.

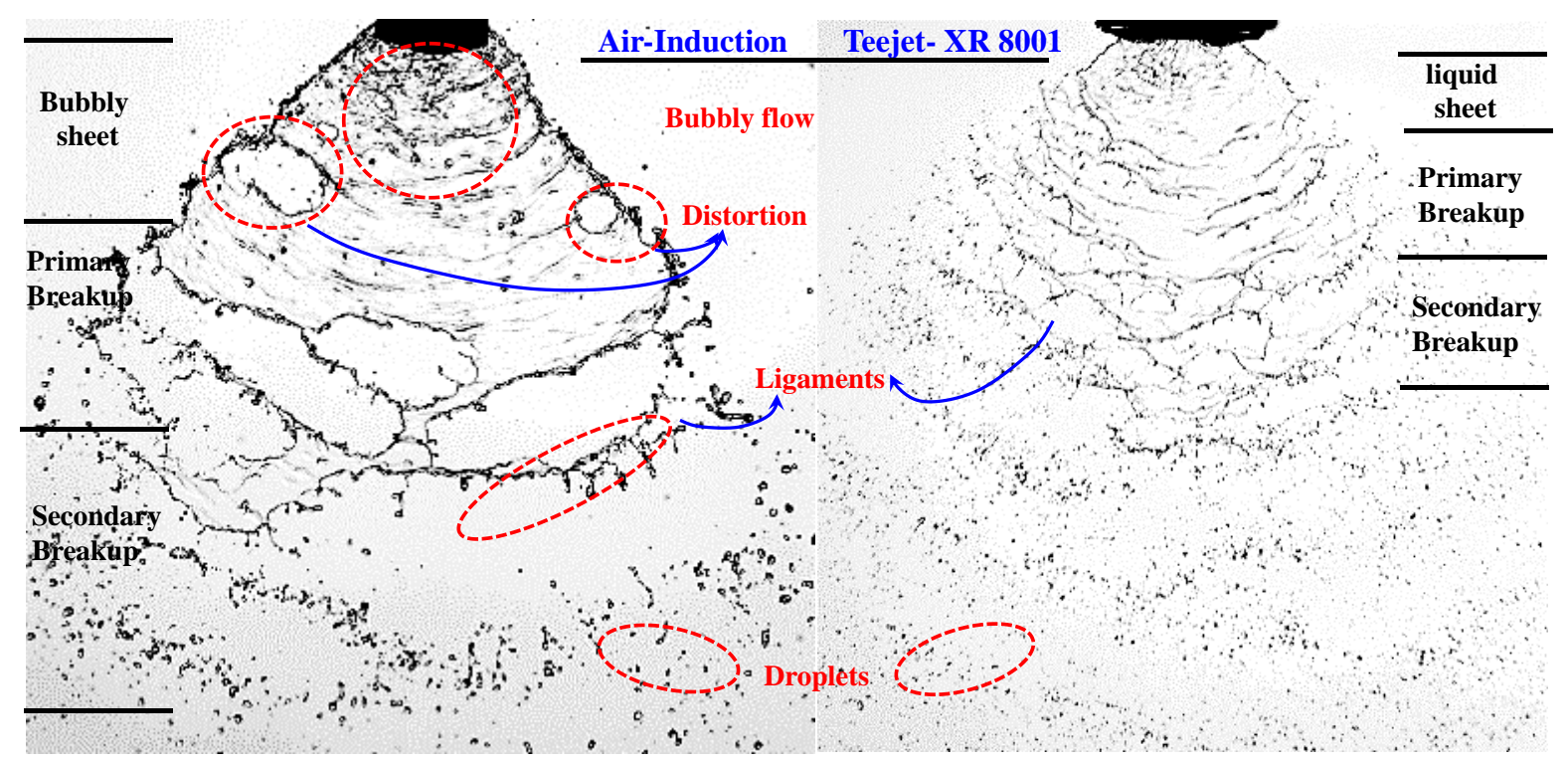

Figure 3 Typical structure of spray from an air induction nozzle compared to conventional flat fan nozzle. With break up regions. 


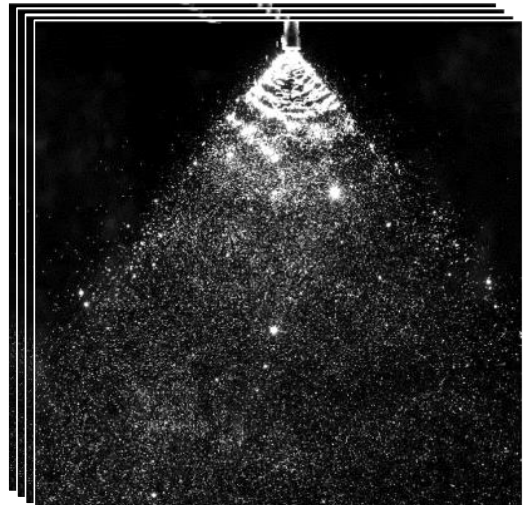

Instantaneous images

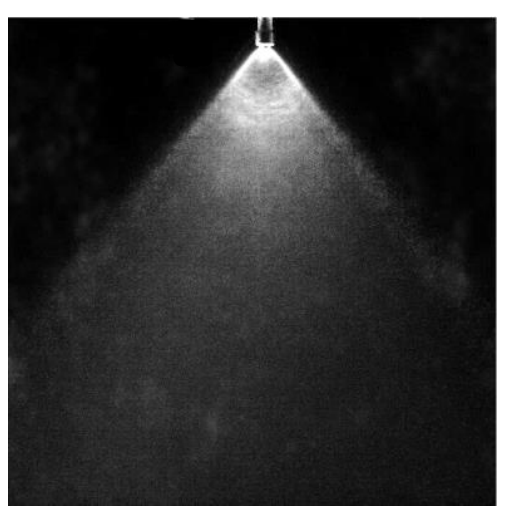

Averaged images

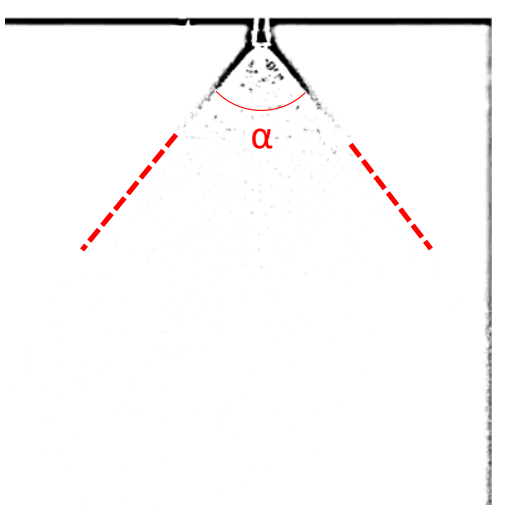

Binarized edge detected images

Figure 4 Spray angle measurement procedure and method. Image processing used to detect sharp edges on the averaged images.

Spray angle generally showed a slight decay with increasing mixing chamber length. However, This trend is not always applied. The given range is chosen to show chaotic phenomena in a multiphase ejector. Based on our preliminary tests, a minimum length for the mixing chamber is needed to provide stable spray. For the current geometry $7 \mathrm{~mm}$ is found chaotic and even $11 \mathrm{~mm}$ is not entirely stable. As the results in Fig. 5 demonstrate, spray structure changes, and spray angle decays drastically in some cases. Mixing chamber length as an individual parameter was found to enhance the stability of the spray while slightly decreasing the spray angle, however, a combination of divergent angle merged with this parameter, introduced a combined effect. A change in divergent angle for longer mixing chambers (where the spray is most stable) doesn't show a great impact on the spray angle. In contrast, for shorter mixing chambers, too narrow or too wide divergent angles lead to chaotic mixing. The chaotic cases here are $[H=11, \theta=0]$ where the spray turned into a jet column, and $[H=7, \theta=40]$ where the spray angle drastically decayed.

The test result for liquid mass flowrate and air to liquid ratio for variation of $H$ and $\theta$ is given in Fig. 6. $A L R$ is an important parameter in air induction nozzles controlled by geometrical parameters. The nozzle was basically designed for $0.6 \mathrm{lit} / \mathrm{min}$ flowrate and the two geometrical parameters showed a minor yet important impact on the studied values. The general trend suggests that both liquid and gas flowrate tend to slightly decrease with increasing mixing chamber. However, for shorter mixing chambers, 0 and 40 degrees jet-pump openings showed a sharp increment in air flowrate. The sudden change behavior can be related to the
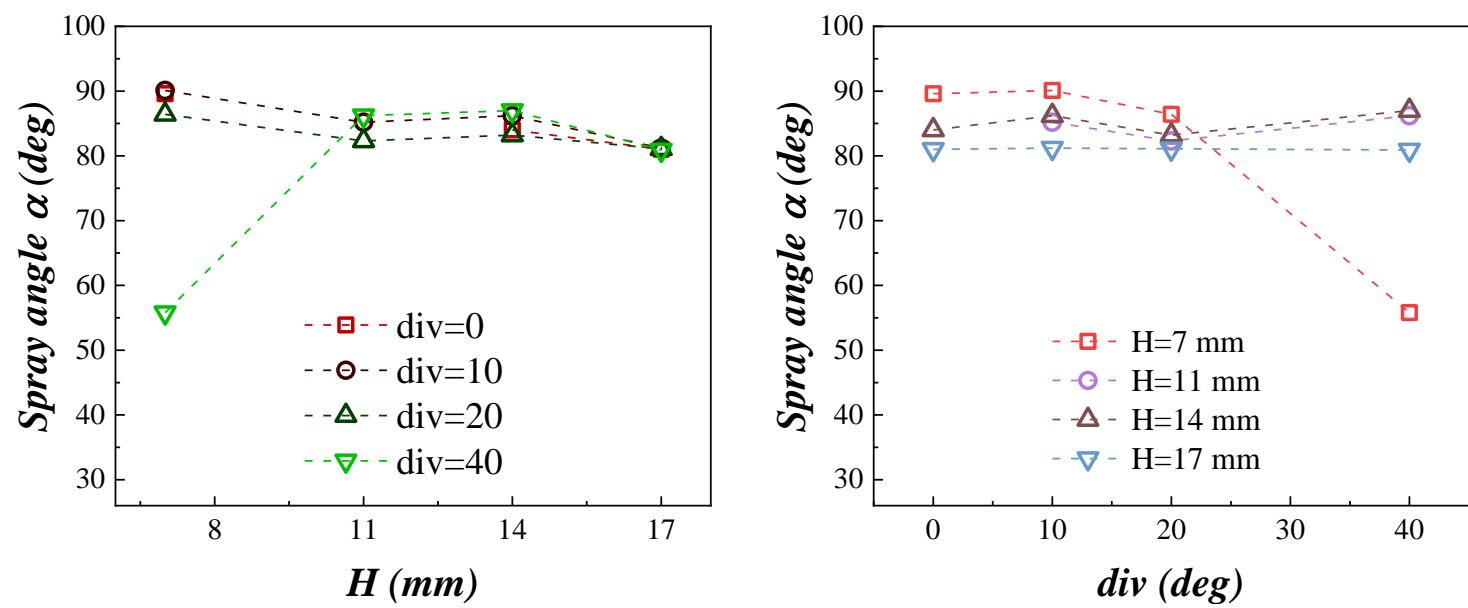

Figure 5 Spray angle with variation of mixing chamber length and jet-pump divergent angle 

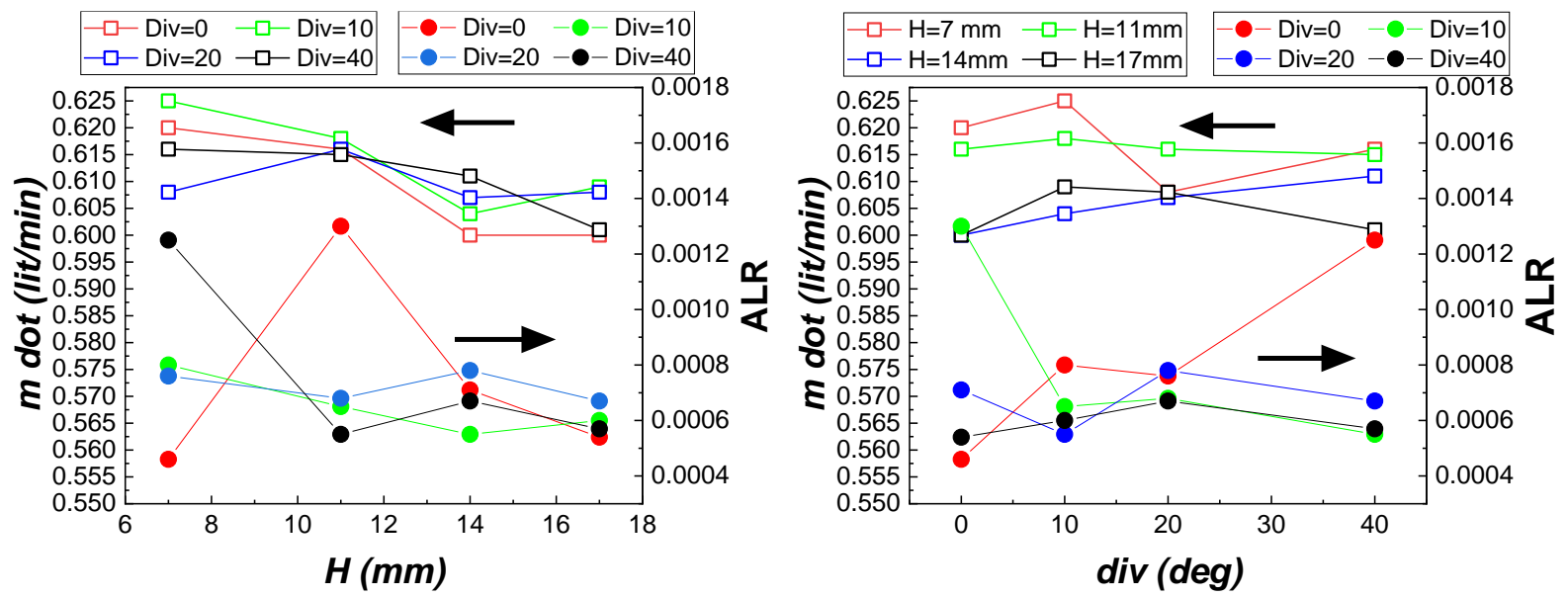

Figure 6 Liquid flowrate and air to liquid mass ratio (ALR) with variation of mixing chamber length and jet-pump divergent angle. (hollow rectangle scatters represent quantities for $m$ dot and solid circle scatters represent ALR)

vortex size and position of the liquid-air mixture inside the mixing chamber, although the physics of internal flow is unknown in the experimental phase of this study.

The droplet size distribution in small $\left(D_{v 0.1}\right)$, volume median $\left(D_{v 0.5}\right)$, and large drop diameter $\left(D_{v 0.9)}\right)$ ranges are given in Fig.7 along with the dimensionless span factor for a stable case. The parameter indicates the uniformity of the drop size distribution of a cut section as a single number. The closer this number is to zero, the more uniform the spray.

$$
\text { Span }=\frac{D_{v 0.9}-D_{v 0.1}}{D_{v 0.5}}
$$

With increasing the mixing chamber length, the mean droplet size slightly increases in all size ranges within a more uniform range. Volume median diameter and span are also shown in Fig. 8 for variation of chamber length in contrast with divergent angle. The effect of the jet-pump divergence on the droplet size was similar to that of spray angle and $A L R$ where a divergent of 10 and 20 degrees enhanced the nozzle performance with larger droplets and better uniformity factor where the performance decayed with divergent 40 and hindered with 10 . Mixing chamber length was found to effectively increase the droplet size and reduce the span factor for all divergent cases..
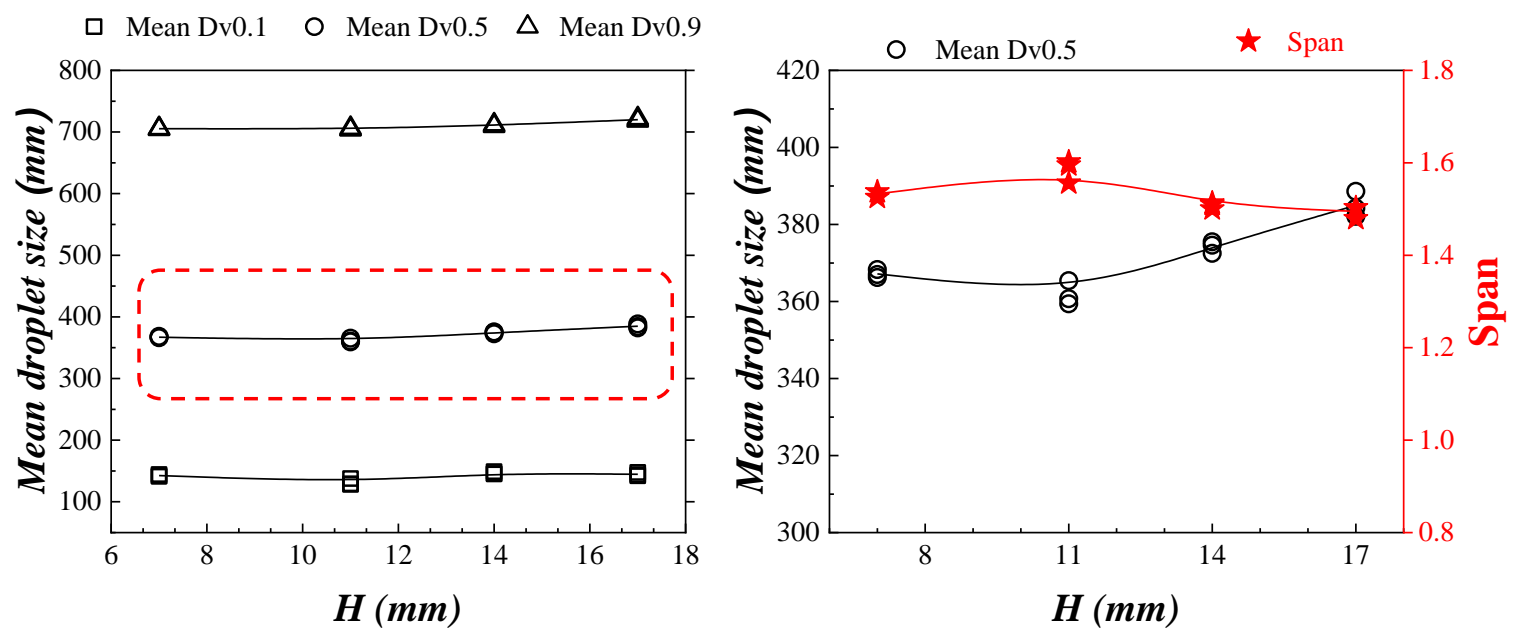

Figure 7 Droplet size class distribution and uniformity span factor for $\theta=10$ deg at axial distance of $300 \mathrm{~mm}$ 

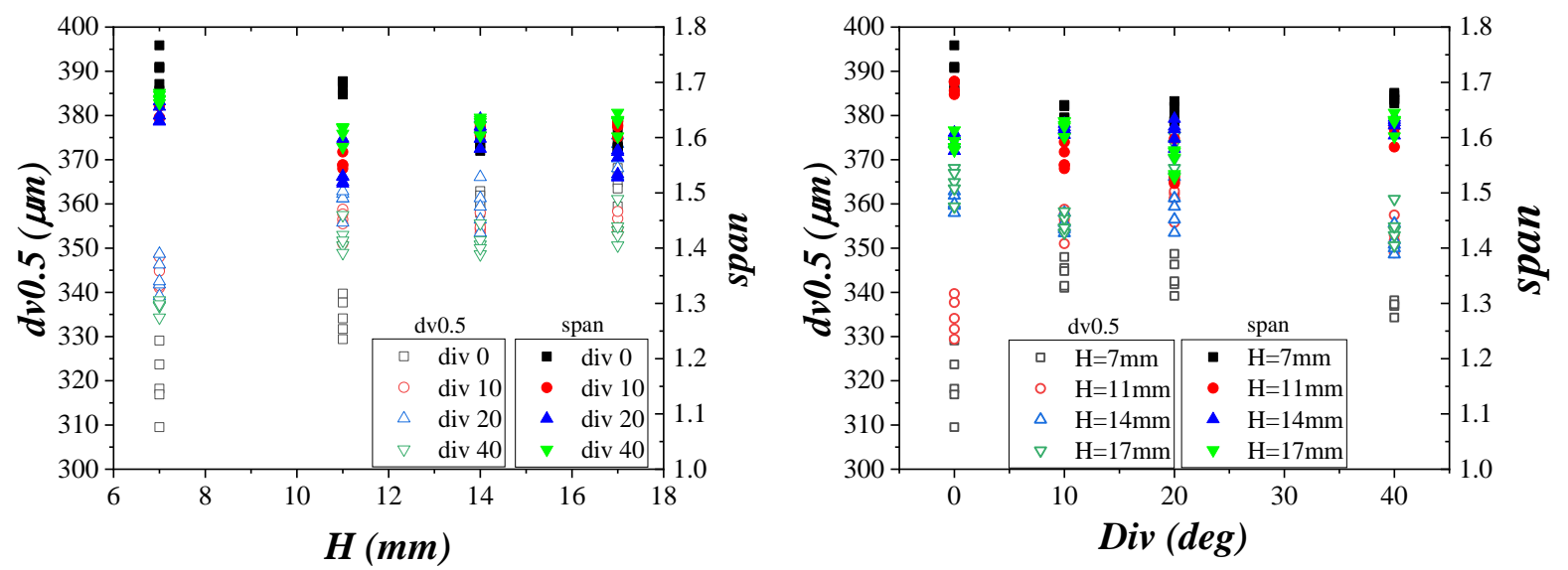

Figure 8 Droplet size and uniformity factor as functions of mixing chamber length and jet-pump divergent angle

\section{Conclusions}

An in-house air induction nozzle was designed and manufactured for various components and geometrical combinations to perform an experimental study on the atomizer performance. The experimental approach was employed to examine the droplet size distribution, spray angle, air, and liquid flow rate, and correspondingly, the $A L R$. Geometrical parameters were found to have a great impact on the performance of the air induction nozzle.

A combination of mixing chamber length and jet-pump divergent angle affects spray stability where the short mixing chamber and too short or too wide divergent angle cause the chaotic flow. A longer mixing chamber produces spray with larger droplet size and enhances the droplet uniformity factor in size where slightly decreases both liquid and gas flow rate as well as spray angle. The divergent angle on the other hand needs to be kept within a certain range. 10 and 20-degree divergent angles were found to have the best performance where 0 and 40 degrees showed a drastic decay in spray angle, droplet size, and uniformity when enhanced the value of $A L R$.

\section{Acknowledgments}

This work was carried out with the support of "Cooperative Research Program for Agriculture Science and Technology Development", Project number: PJ01557502 Rural Development Administration, Republic of Korea, and the Basic Science Research Program through the National Research Foundation of Korea (NRF) and funded by the Ministry of Education (Grant number: NRF2018R1D1A1B07040902).

\section{Nomenclature}

AIN Air Induction Nozzle $\left[\mathrm{m} \mathrm{s}^{-2}\right]$

$A L R \quad$ Air to Liquid mass flow ratio $\left[\dot{\mathrm{m}}_{\mathrm{a}} / \dot{\mathrm{m}}_{\mathrm{l}}\right]$

$\theta$ (Div) Divergent angle [deg]

$H \quad$ Mixing chamber height [mm]

da Air inlet diameter [mm]

$d p \quad$ Pre-orifice diameter [mm]

$d t \quad$ Throat diameter [mm]

$V \quad$ Tip V-cut angle [deg]

$d_{v 0.1}$ A diameter which $10 \%$ of droplets are smaller than that $[\mu \mathrm{m}]$

\section{References}

[1] N. K. V. Alfen, Encyclopedia of Agriculture and Food Systems. London, UK, 2014.

[2] D. Nuyttens, K. Baetens, M. De Schampheleire, and B. Sonck, "Effect of nozzle type, size and pressure on spray droplet characteristics," Biosystems Engineering, vol. 97, pp. 333-345, 2007/07/01/ 2007. 
[3] D. Foqué, P. Braekman, J. G. Pieters, and D. Nuyttens, "A vertical spray boom application technique for conical bay laurel (Laurus nobilis) plants," Crop Protection, vol. 41, pp. 113-121, 2012.

[4] T. Arvidsson, L. Bergström, and J. Kreuger, "Spray drift as influenced by meteorological and technical factors," Pest Management Science, vol. 67, pp. 586-598, 2011.

[5] M. Al Heidary, J. P. Douzals, C. Sinfort, and A. Vallet, "Influence of spray characteristics on potential spray drift of field crop sprayers: A literature review," Crop Protection, vol. 63, pp. 120-130, 2014/09/01/2014.

[6] I. Cornacchia, S. Tomas, J.-P. Douzals, and D. Courault, "Assessment of Airborne Transport of Potential Contaminants in a Wind Tunnel," Journal of Irrigation and Drainage Engineering, vol. 146, p. 04019031, 2020.

[7] D. Nuyttens, M. De Schampheleire, P. Verboven, and B. Sonck, "Comparison between indirect and direct spray drift assessment methods," Biosystems Engineering, vol. 105, pp. 2-12, 2010/01/01/ 2010.

[8] D. Nuyttens, W. A. Taylor, M. De Schampheleire, P. Verboven, and D. Dekeyser, "Influence of nozzle type and size on drift potential by means of different wind tunnel evaluation methods," Biosystems Engineering, vol. 103, pp. 271-280, 2009/07/01/ 2009.

[9] B. Zhang, Q. Tang, L.-p. Chen, R.-r. Zhang, and M. Xu, "Numerical simulation of spray drift and deposition from a crop spraying aircraft using a CFD approach," Biosystems Engineering, vol. 166, pp. 184-199, 2018/02/01/2018.

[10] R. A. Dafsari, F. Vashahi, and J. Lee, "Effect of Swirl Chamber Length on the Atomization Characteristics of a Pressure-Swirl Nozzle " Atomization and Spray, vol. 27, pp. 1-16, 2017.

[11] A. H. Lefebvre and V. G. McDonell, Atomization and Spray. Boca Raton: Taylor \& Francis, 2017.

[12] A. Vallet and C. Tinet, "Characteristics of droplets from single and twin jet air induction nozzles: A preliminary investigation," Crop Protection, vol. 48, pp. 63-68, 2013/06/01/ 2013.

[13] ASABE, "Standard S572. 1: Spray nozzle classification by droplet spectra," 2009.

[14] H. Guler, H. Zhu, E. Ozkan, R. Derksen, and C. Krause, "Wind Tunnel Evaluation of Drift Reduction Potential and Spray Characteristics with Drift Retardants at High Operating Pressure," G. Lindner, M. Salyani, and C. Martin, Eds., ed West Conshohocken, PA: ASTM International, 2008, pp. 72-80.

[15] F. Vashahi, S. Ra, Y. Choi, and J. Lee, "A preliminary investigation of the design parameters of an air induction nozzle," Journal of Mechanical Science and Technology, vol. 31, pp. 3297-3303, July 012017.

[16] F. Vashahi, S. Ra, Y. Choi, and J. K. Lee, "Influence of Design Parameters on the Air/Liquid Ratio of an Air Induction Nozzle," Journal of Mechanics, vol. 34, pp. 375-385, 2017.

[17] M. C. Butler Ellis, T. Swan, P. C. H. Miller, S. Waddelow, A. Bradley, and C. R. Tuck, "PM-Power and Machinery: Design Factors affecting Spray Characteristics and Drift Performance of Air Induction Nozzles," Biosystems Engineering, vol. 82, pp. 289-296, 2002/07/01/ 2002.

[18] J. H. Combellack, N. M. Westen, and R. G. Richardson, "A comparison of the drift potential of a novel twin fluid nozzle with conventional low volume flat fan nozzles when using a range of adjuvants," Crop Protection, vol. 15, pp. 147-152, 1996/03/01/ 1996.

[19] L. Zheng, C. Cao, L. Cao, Z. Chen, Q. Huang, and B. Song, "Bounce Behavior and Regulation of Pesticide Solution Droplets on Rice Leaf Surfaces," Journal of Agricultural and Food Chemistry, vol. 66, pp. 1156011568, 2018/11/07 2018.

[20] G. J. Dorr, A. J. Hewitt, S. W. Adkins, J. Hanan, H. Zhang, and B. Noller, "A comparison of initial spray characteristics produced by agricultural nozzles," Crop Protection, vol. 53, pp. 109-117, 2013/11/01/2013.

[21] M. Ferrari, L. Liggieri, and R. Miller, Drops and Bubbles in Contact with Solid Surfaces, 2012.

[22] M. E. Poulsen, M. Wenneker, J. Withagen, and H. B. Christensen, "Pesticide residues in individual versus composite samples of apples after fine or coarse spray quality application," Crop Protection, vol. 35, pp. $5-14,2012 / 05 / 01 / 2012$.

[23] L.-H. Chien, J.-J. Xu, T.-F. Yang, and W.-M. Yan, "Experimental study on water spray uniformity in an evaporative condenser of a water chiller," Case Studies in Thermal Engineering, vol. 15, p. 100512, 2019/11/01/ 2019.

[24] J. C. Ferguson, C. C. O'Donnell, B. S. Chauhan, S. W. Adkins, G. R. Kruger, R. Wang, et al., "Determining the uniformity and consistency of droplet size across spray drift reducing nozzles in a wind tunnel," Crop Protection, vol. 76, pp. 1-6, 2015/10/01/2015. 